Article

\title{
Iodine-doping-assisted tunable introduction of oxygen vacancies on bismuth tungstate photocatalysts for highly efficient molecular oxygen activation and pentachlorophenol mineralization
}

\author{
Shengyao Wang †, Zhongliang Xiong †, Nan Yang, Xing Ding \#, Hao Chen * \\ College of Science, Huazhong Agricultural University, Wuhan 430070, Hubei, China
}

\section{A R T I C L E I N F O}

Article history:

Received 27 February 2020

Accepted 30 March 2020

Published 5 October 2020

\section{Keywords:}

Iodine doping

Oxygen vacancy

Bismuth tungstate

Photocatalyst

Molecular oxygen activation

$\mathrm{NaPCP}$

\begin{abstract}
A B S T R A C T
In this work, the tunable introduction of oxygen vacancies in bismuth tungstate was realized via a simple solvothermal method with the assistance of iodine doping. With the predictions afforded by theoretical calculations, the as-prepared bismuth tungstate was characterized using various techniques, such as X-ray diffraction, Raman spectroscopy, scanning electron microscopy, transmission electron microscopy, X-ray photoelectron spectroscopy, electron spin resonance spectroscopy, and UV-Vis diffuse reflectance spectroscopy. The different concentrations of the oxygen vacancies on bismuth tungstate were found to be intensely correlated with iodine doping, which weakened the lattice oxygen bonds. Owing to the sufficient oxygen vacancies introduced in bismuth tungstate as a result of iodine doping, the molecular oxygen activation was remarkably enhanced, thus endowing bismuth tungstate with high activity for the photocatalytic degradation of sodium pentachlorophenate. More encouraging is the total organic carbon removal rate of sodium pentachlorophenate over iodine-doped bismuth tungstate that exceeded $90 \%$ in only $2 \mathrm{~h}$ and was 10.6 times higher than that of the pristine bismuth tungstate under visible light irradiation. Moreover, the mechanism, through which the degradation of sodium pentachlorophenate over iodine-doped bismuth tungstate is enhanced, was speculated based on the results of radical detection and capture experiments. This work provides a new perspective for the enhanced photocatalytic degradation of organochlorine pesticides from the oxygen vacancy-induced molecular oxygen activation over iodine-doped bismuth tungstate.
\end{abstract}

(C) 2020, Dalian Institute of Chemical Physics, Chinese Academy of Sciences. Published by Elsevier B.V. All rights reserved.

\section{Introduction}

In recent years, with rapid industrialization, urbanization, and population growth, environmental pollution attributed to the improper use of pesticides has attracted significant concern globally [1-3]. Much attention has been drawn to the detrimental effects of long-term residues of pesticides and their intermediate degradation products in the environment [4-7]. In this context, many scientists have devoted their efforts to the development of advanced oxidation technologies for the treat-

\footnotetext{
* Corresponding author. Tel/Fax: +86-27-87288246; E-mail: hchenhao@mail.hzau.edu.cn

* Corresponding author. E-mail: dingx@mail.hzau.edu.cn

† These authors contributed equally to this work.

This work was supported by the National Natural Science Foundation of China (51872107, 21607047, 51572101, 51902121), Natural Science Foundation of Hubei Province (2016CFB193, 2019CFB322), and Fundamental Research Funds for the Central Universities (2662015QD047, 2662016PY088, 2662015PY047).

DOI: S1872-2067(19)63506-0 | http://www.sciencedirect.com/science/journal/18722067 | Chin. J. Catal., Vol. 41, No. 10, October 2020
} 
ment of residual pesticides in environmental waters [8-10]. Among these technologies, photocatalysis is considered to be the most promising strategy in the area of environmental recommendation by virtue of the inexhaustible and environmentally friendly feature of solar energy [11]. Since the discovery of photocatalysis in 1972 [12], photocatalytic technology has been widely accepted for the activation of molecular oxygen by photogenerated carriers [13-18]. The contaminants are likely to react with these generated oxygen radicals, thus causing their degradation. Unfortunately, considering the difficulty in the achieving a compromise between the light absorption and the redox ability of the photocatalysts, highly efficient photocatalysis processes for molecular oxygen activation are desirable for environmental application, although combining the advantages of light absorption and redox ability remains challenging $[19,20]$.

Recently, defect engineering, particularly the introduction of oxygen vacancies (OVs), was certified as an efficient strategy to engineer the bandgap and tailor the electronic structures of photocatalysts, thereby appreciably boosting the photocatalytic efficiencies [21-23]. The existence of defect states can also effectively trap charge carriers, thus accelerating the separation of photogenerated electron-hole pairs. OVs with abundant trapped electrons could act as active sites for the activation of inert gas molecules; thus, significant effort has been devoted to clarifying the inherent functionality of OVs in photocatalysis at the surface molecular level [24]. Many papers have reported that native OVs could easily charge $\mathrm{O}_{2}$ via localized electrons. This suggests that the activation of the photocatalytic molecular oxygen $\left(\mathrm{O}_{2}\right)$ over OVs is a credible alternative to overcome the spin forbidden reactions of $\mathrm{O}_{2}$ in triplet state toward the generation of reactive oxygen species (ROS) [25-27]. The resulting ROS, such as hydroxyl radicals $(\cdot \mathrm{OH})$, superoxide anion radicals $\left(\cdot \mathrm{O}_{2}{ }^{-}\right)$, and singlet oxygen $\left({ }^{1} \mathrm{O}_{2}\right)$, are generally considered to exhibit more oxidizability than $\mathrm{O}_{2}$. Despite the numerous pioneering works centered on OV construction, the strategy for the regulation of the OV concentration on the photocatalyst is still in its infancy stage, leaving enormous room for further exploration [28-31]. Therefore, it is of great significance and importance to establish a method for controlled introduction of OVs to disclose the potential role of OVs for enhanced molecular oxygen activation [32-35].

As one of the simple members of the Aurivillius family, bismuth tungstate $\left(\mathrm{Bi}_{2} \mathrm{WO}_{6}\right)$ is regarded as a promising photocatalyst by virtue of its intrinsic chemical inertness, appropriate band potentials, and unique layered structure [36-38]. Consisting of alternating stacks of $\left[\mathrm{Bi}_{2} \mathrm{O}_{2}\right]^{2+}$ layers and perovskite-like $\left[\mathrm{WO}_{4}\right]^{2-}$ layers with oxygen atom sharing, $\mathrm{Bi}_{2} \mathrm{WO}_{6}$ possesses exceptional characteristics of facile oV generation under $\mathrm{O}_{2}$-deficient thermal conditions due to the low energy of $\mathrm{Bi}-\mathrm{O}$ bonds. In addition, doping of some non-metal elements is a valid route to adjust the metal-oxygen bonds in $\mathrm{Bi}_{2} \mathrm{WO}_{6}$ based on the previous report [39]. For example, the presence of $\mathrm{F}$ atoms was reported to remove the oxygen atom in F-doped $\mathrm{Bi}_{2} \mathrm{WO}_{6}$. Bearing these aspects in mind, we intend to choose another halogen anion as a dopant for developing a novel iodine-doped $\mathrm{Bi}_{2} \mathrm{WO}_{6}$ catalyst, where $\mathrm{I}^{-}$is bonded with the $\mathrm{Bi}$ atom of $\mathrm{Bi}_{2} \mathrm{WO}_{6}$ to weaken the energy of $\mathrm{Bi}-\mathrm{O}$ bonds [40]. Under the $\mathrm{O}_{2}$-deficient thermal condition, the concentration of the OVs was regulated by the doping content of iodine.

In the present study, iodine-doped $\mathrm{Bi}_{2} \mathrm{WO}_{6}$ catalysts with OVs were synthesized in a reductive ethylene glycol solvent via a facile and simple solvothermal method. With the predictions afforded by theoretical calculations, various characteristic methods were employed to investigate the impacts of iodine doping on the physicochemical properties of $\mathrm{Bi}_{2} \mathrm{WO}_{6}$. The different concentrations of the OVs in $\mathrm{Bi}_{2} \mathrm{WO}_{6}$ were further detected by electron spin resonance spectroscopy (ESR) to prove the close correlation between iodine doping and OV introduction. The influence of the abundant OVs on the $\mathrm{Bi}_{2} \mathrm{WO}_{6}$ surface on its photocatalytic activity in visible light was subsequently investigated by the photocatalytic degradation of sodium pentachlorophenate (NaPCP), a widely used pesticide with high toxicity and slow biodegradation in the environment. With the molecular oxygen activation induced by the OVs, the total organic carbon (TOC) removal rate of iodine-doped $\mathrm{Bi}_{2} \mathrm{WO}_{6}$ was found to be 10.6 times higher than that of the pristine $\mathrm{Bi}_{2} \mathrm{WO}_{6}$ under visible light irradiation. In addition, the mechanism, through which the degradation of NaPCP over iodine-doped $\mathrm{Bi}_{2} \mathrm{WO}_{6}$ is enhanced, was finally speculated based on the results of radical detection and capture experiments.

\section{Experimental}

\subsection{Synthesis of $\mathrm{Bi}_{2} \mathrm{WO}_{6}$ and iodine-doped $\mathrm{Bi}_{2} \mathrm{WO}_{6}$}

All samples were synthesized by a simple solvothermal method. The specific steps are as follows. Under magnetic stirring, $\mathrm{Bi}\left(\mathrm{NO}_{3}\right)_{3} \cdot 5 \mathrm{H}_{2} \mathrm{O}(30 \mathrm{~mL}, 0.005 \mathrm{mmol})$ dissolved in ethylene glycol and sodium $\mathrm{NaWO}_{4} \cdot 5 \mathrm{H}_{2} \mathrm{O}\left(\mathrm{Bi}_{2} \mathrm{WO}_{6}\right.$ stoichiometric ratio) dissolved in water were uniformly mixed. After the continuous addition of $20 \mathrm{~mL}$ of different concentrations of $\mathrm{KI}$ aqueous solution $(0,0.06,0.12,0.18$, or $0.24 \mathrm{~mol} / \mathrm{L})$, the mixed liquor was stirred continuously for $20 \mathrm{~min}$. The resulting reaction precursor solution was then sealed in an $80 \mathrm{~mL}$ PTFE lined stainless steel autoclave and heated at $160{ }^{\circ} \mathrm{C}$ for $12 \mathrm{~h}$. Finally, the iodine-doped bismuth tungstate product was collected by centrifugation, washed severally with ethanol and distilled water repeatedly, and then dried in an oven at $60{ }^{\circ} \mathrm{C}$ for $12 \mathrm{~h}$. To study the effect of the iodine doping concentration, in accordance with the concentration of KI added during the synthesis, the resulting products were designated as BWO, BWO-0.06, BWO-0.12, BWO-0.18, and BWO-0.24, respectively.

\subsection{Characterization}

X-ray diffraction (XRD) patterns of the samples were recorded on a Bruker D8 Advance X-ray diffractometer with $\mathrm{Cu} K_{\alpha}$ radiation $(\lambda=1.5418 \mathrm{~nm})$ and irradiated at a scan rate of $5^{\circ} /$ min in the range of $5^{\circ}-80^{\circ}$. The X-ray tube voltage and current were set at $45 \mathrm{kV}$ and $50 \mathrm{~mA}$, respectively. The morphology and microstructure of the samples were characterized by scanning electron microscopy (SEM, JEOL 6700-F) and transmission electron microscopy (TEM, JEOL JEM-2010). Induc- 
tively coupled plasma analysis (ICP, Agilent 7900) was conducted to determine the iodine doping amount of the as-prepared samples that were pretreated with chloroazotic acid and diluted for subsequent analysis. The UV-vis diffuse reflectance spectra (DRS) of the prepared samples in the range of 200-800 nm were recorded in the absorption mode using a PerkinElmer lambda 650s UV-vis spectrophotometer. The surface elemental composition of the sample was analyzed by X-ray photoelectron spectroscopy (XPS) using an XSAM800 system with $\mathrm{Mg} K_{\alpha} \mathrm{X}$-ray as the excitation source, and all the binding energies were referenced to the $\mathrm{C} 1 s$ peak at $284.6 \mathrm{eV}$ of the surface amorphous carbon. The Raman spectrum was collected using a confocal microscope, and the wavelength of the excitation laser was $514 \mathrm{~nm}$. The adsorption and desorption isotherms, pore size distribution, and specific surface area of nitrogen were measured at $-196{ }^{\circ} \mathrm{C}$ using a surface area and pore size analyzer. For the electron spin resonance spectroscopy (ESR) measurements, 5,5-dimethyl-1-pyrroline- $N$-oxide (DMPO) was employed as a free radical trapping reagent to detect active oxygen species generated in a photocatalytic system on a Magnettech MS-5000 EPR spectrometer under visible light. The TOC content was analyzed using a Shimadzu TOC-LCSH/CPH analyzer.

\subsection{Photocatalytic activity test}

The photocatalytic activity of the sample was evaluated by the photocatalytic degradation of NaPCP. Photocatalytic degradation experiments were carried out using a simulated solar illumination device with a $300 \mathrm{~W}$ Xe lamp light source and a $400 \mathrm{~nm}$ cut-off filter. The constant temperature of $20{ }^{\circ} \mathrm{C}$ was maintained in the double glass container by circulating the condensate. A $25 \mathrm{mg}$ sample of the as-prepared bismuth tungstate was dispersed in NaPCP $\left(50 \mathrm{~mL}, 30 \times 10^{-6} \mathrm{mg} / \mathrm{L}\right.$ ). The catalyst suspension was subjected to magnetic stirring under a dark adsorption reaction condition for 60 min until adsorption-desorption equilibrium was attained. During the illumination, a $2 \mathrm{~mL}$ aliquot of the sample was centrifuged at $10 \mathrm{~min}$ intervals for the subsequent analysis. The concentration of NaPCP was analyzed by recording the signal intensity using a high-performance liquid chromatography (HPLC) instrument equipped with a UV detector at $227 \mathrm{~nm}$. In the capture experi-
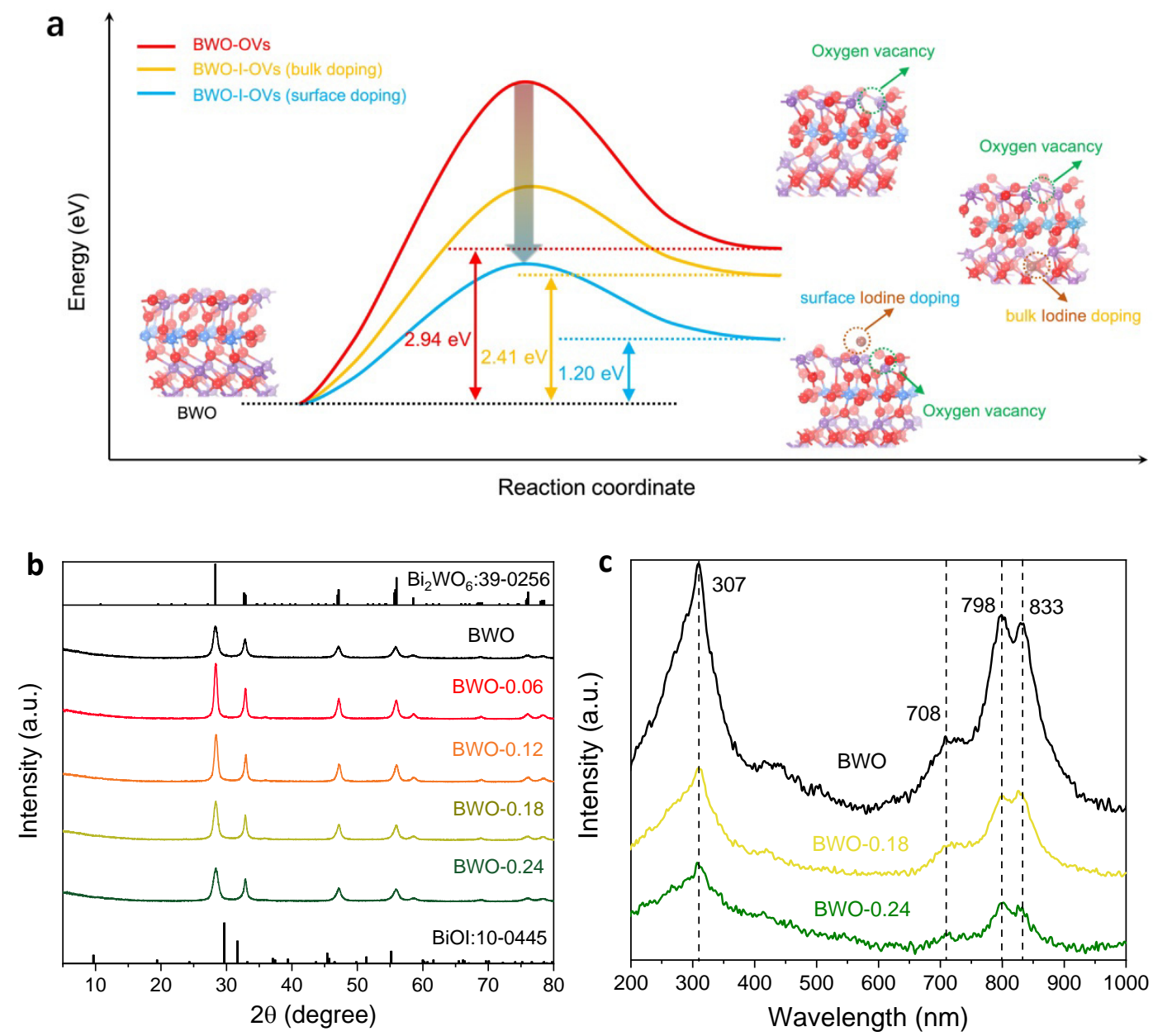

Fig. 1. DFT calculations for the OV formation energy on $\mathrm{Bi}_{2} \mathrm{WO}_{6}$ and iodine-doped $\mathrm{Bi}_{2} \mathrm{WO}_{6}(\mathrm{a}$ ); $\mathrm{XRD}$ patterns (b) and Raman spectra (c) of the as-prepared $\mathrm{Bi}_{2} \mathrm{WO}_{6}$ and iodine-doped $\mathrm{Bi}_{2} \mathrm{WO}_{6}$ catalysts. 
ments, isopropanol (IPA), triethanolamine (TEOA), superoxide dismutase (SOD), $\mathrm{CCl}_{4}$, and carotene were applied as scavengers for ${ }^{\bullet} \mathrm{OH}, \mathrm{h}^{+}, \bullet^{-} \mathrm{O}_{2}^{-}, \mathrm{e}^{-}$, and ${ }^{1} \mathrm{O}_{2}$, respectively.

\subsection{Theoretical calculation}

All plane-wave density functional theory (DFT) calculations were performed using the Vienna Ab-initio Simulation Package (VASP) software [41,42]. The generalized gradient approximation by Perdew, Burke, and Ernzerhof was used for the exchange-correlation energy. The ionic cores were described by projector-augmented wave potentials $[43,44]$. All structural optimizations were conducted using a plane-wave expansion for the basis set with a cutoff energy of $380 \mathrm{eV}$. For the bulk $\mathrm{Bi}_{2} \mathrm{WO}_{6}$ geometry optimization, the atomic coordinates were fully relaxed with $3 \times 1 \times 1$ Monkhorst-Pack grids. The stoichiometric surface of the (001) facet constructed by a $2 \times 2 \times 1$ supercell (144 atoms) was used to model the surface of the experimentally prepared $\mathrm{Bi}_{2} \mathrm{WO}_{6}$, where the atomic positions of the top six layers of atoms were relaxed; however, the bottom layers were kept fixed at their bulk position. A vacuum region of $15 \AA$ along the z-axis was used to eliminate the interactions between the neighboring cells of the slab models under periodic conditions. An iodine dopant was created on the $1 \times 2 \times 2$ supercell by removing an $\mathrm{O}$ atom between two adjacent $\mathrm{Bi}$ atoms. For all the slab calculations, the Brillouin zones were sampled with $3 \times 1 \times 1$ Monkhorst-Pack grids. The convergence with the force on each atom was set below $0.02 \mathrm{eV} / \AA$, and the energy on each atom was within $1 \times 10^{-5} \mathrm{eV}$ for all calculations.

\section{Results and discussion}

DFT calculations were firstly conducted to predict the impact of iodine doping on the OV formation over $\mathrm{Bi}_{2} \mathrm{WO}_{6}$ (Figure 1a). Considering the two cases of surface and bulk doping, the oxygen atoms on the surface and inside $\mathrm{Bi}_{2} \mathrm{WO}_{6}$ were replaced with iodine atoms, as the model for studying the difference in OV formation. For the $\mathrm{Bi}_{2} \mathrm{WO}_{6}$ catalyst without iodine, $2.94 \mathrm{eV}$ is required to remove an oxygen atom forming the OVs. With surface iodine doping, the formation energy of the OVs in iodine-doped $\mathrm{Bi}_{2} \mathrm{WO}_{6}$ could be decreased to $1.20 \mathrm{eV}$. Although the OVs in the bulk iodine-doped $\mathrm{Bi}_{2} \mathrm{WO}_{6}$ require $2.41 \mathrm{eV}$, which is higher than that on the surface iodine-doped $\mathrm{Bi}_{2} \mathrm{WO}_{6}$, it still shows a decrease in the formation of OVs compared to the case of the pristine $\mathrm{Bi}_{2} \mathrm{WO}_{6}$, which may be attributed to the weakening effect of the $\mathrm{Bi}-\mathrm{O}$ bonds owing to the introduced iodine dopant. The above results indicated that the iodine doping could decrease the formation energy of OVs, thus promoting the $\mathrm{OV}$ generation on $\mathrm{Bi}_{2} \mathrm{WO}_{6}$. Inspired by these calculation results, we used potassium iodide as the dopant to synthesize iodine-doped $\mathrm{Bi}_{2} \mathrm{WO}_{6}$. The crystalline phase of the as-prepared $\mathrm{Bi}_{2} \mathrm{WO}_{6}$ was first investigated by XRD studies. As shown in Figure $1 \mathrm{~b}$, the pure $\mathrm{Bi}_{2} \mathrm{WO}_{6}$ catalyst showed high agreement with the standard card (JCPDS No. 39-0256). It is worth noting that despite the introduction of the iodine dopant, only the diffraction peak corresponding to $\mathrm{Bi}_{2} \mathrm{WO}_{6}$ was observed on the patterns of BWO, BWO-0.06, BWO-0.12, BWO-0.18, and BWO-0.24, indicating that the iodine dopant has no effect on the formation of BiOI (JCPDS No. 11-0445). To further confirm the iodine introduction form, Raman spectroscopy was employed to study the lattice strain of the iodine-doped $\mathrm{Bi}_{2} \mathrm{WO}_{6}$. It was found that the intensity of the peak at $307 \mathrm{~cm}^{-1}$, attributed to the Bi-O bending vibration, appreciably decreased with the increase in the $\mathrm{I}^{-}$addition amount during the synthetic process, which may be ascribed to the decrease in the number of $\mathrm{Bi}-\mathrm{O}$ bonds and crystallinity of $\mathrm{Bi}_{2} \mathrm{WO}_{6}$ caused by iodine doping [45].

The microstructures of the pure $\mathrm{Bi}_{2} \mathrm{WO}_{6}$ (BWO) and iodine-doped $\mathrm{Bi}_{2} \mathrm{WO}_{6}$ (BWO-0.18) catalysts were further investigated by SEM and TEM. As shown in Figures $2 a$ and $2 b$, the SEM images showed that BWO and BWO-0.18 with stereoscopic
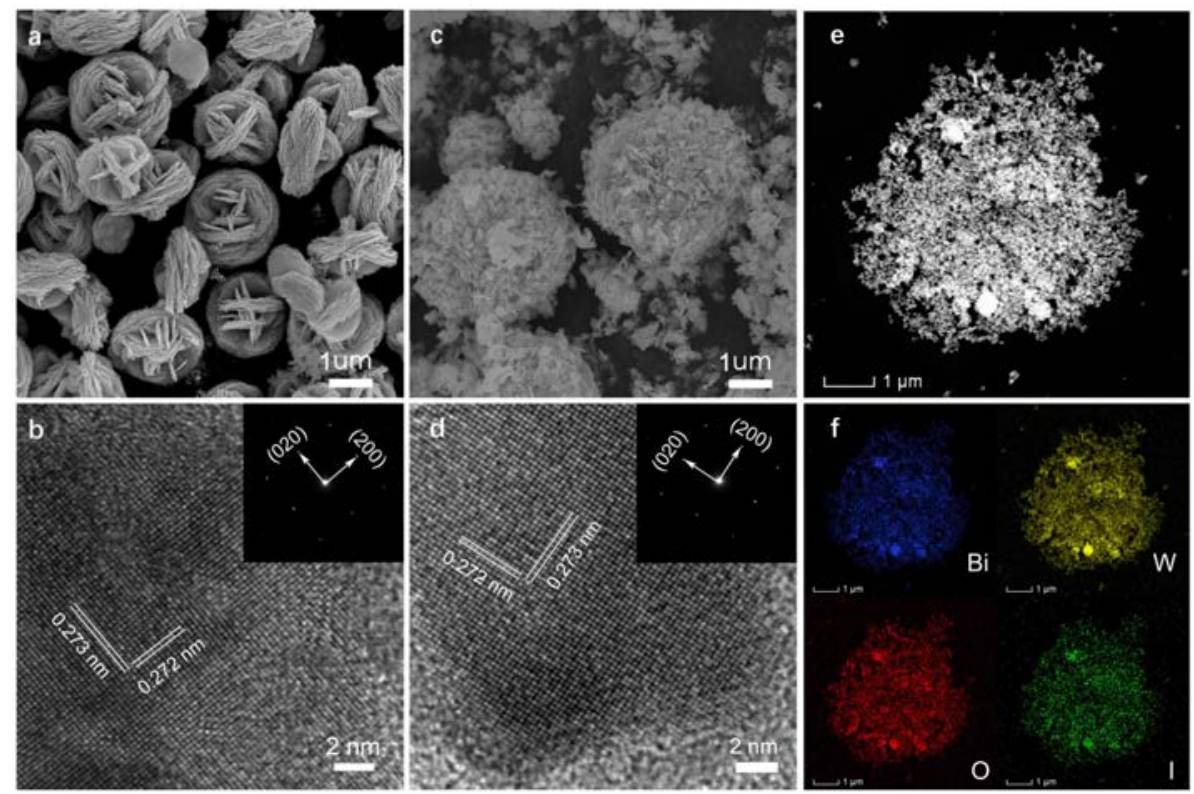

Fig. 2. FESEM images and HRTEM images of (a, b) BWO and (c, d) BWO-0.18, and the EDX elemental mapping (e, f) of BWO-0.18. 
Table 1

Iodine content of the as-prepared $\mathrm{Bi}_{2} \mathrm{WO}_{6}$ samples analyzed by ICP.

\begin{tabular}{lcc}
\hline Sample & $\begin{array}{c}\mathrm{I}^{\mathrm{Bi}} \mathrm{BiO}_{6} \text { weight percentage } \\
(\%)\end{array}$ & $\begin{array}{c}\mathrm{I} / \mathrm{Bi}_{2} \mathrm{WO}_{6} \text { atomic ratio } \\
(\%)\end{array}$ \\
\hline BWO-0.06 & 0.012 & 0.11 \\
BWO-0.12 & 0.037 & 0.34 \\
BWO-0.18 & 0.081 & 0.74 \\
BWO-0.24 & 0.15 & 1.37 \\
\hline
\end{tabular}

three-dimensional structures were assembled by thick nanosheets. BWO is in the shape of a dense persimmon, while BWO-0.18 exhibits flower-like structures with more loose cavities. This loose structure of BWO-0.18 may be caused by the intervening iodine dopant introduced during the solvothermal reaction. The microstructure of the as-prepared material was also analyzed by HRTEM images (Figures $2 \mathrm{c}$ and $2 \mathrm{~d}$ ). Under HRTEM, both BWO and BWO-0.18 were observed to have legible orthorhombic lattice fringes with spaces of 0.272 and 0.273 $\mathrm{nm}$ (Figures 2c and 2d), respectively, ascribed to the (020) and (200) planes of orthorhombic $\mathrm{Bi}_{2} \mathrm{WO}_{6}$, thereby suggesting that both of them are indeed exposed with the $\{001\}$ facets $[46,47]$. To further confirm the presence of iodine, the elemental mapping and energy dispersive X-ray (EDX) spectroscopic analysis of BWO-0.18 were also carried out (Figures 2e and 2f). The distribution of the individual elements, $\mathrm{Bi}, \mathrm{W}, \mathrm{O}$, and I, can be clearly observed, revealing that iodine was uniformly distributed in the BWO-0.18 structure. This was further confirmed by the result of ICP analysis displayed in Table 1, from which the iodine doping content was observed to gradually increase with the addition of iodine during synthesis.

The chemical environments of BWO and BWO-0.18 characterized by XPS are displayed in Figure 3a. The survey XPS implies the presence of $\mathrm{Bi}, \mathrm{W}, \mathrm{O}$, and $\mathrm{C}$ elements in the two samples as well as an enhanced I 3d peak in BWO-0.18. To obtain the direct evidence of iodine doping, the I $3 d$ time-dependent XPS analysis of BWO-01.8 was conducted. The peaks of I $3 d$ located at 630.5 and $618.5 \mathrm{eV}$ show no shift during the $\mathrm{Ar}^{+}$ sputtering, which demonstrated that the iodine dopants were homogeneously incorporated into the lattices of $\mathrm{Bi}_{2} \mathrm{WO}_{6}$ through this synthesis strategy. The high-resolution XPS spectra of Bi $4 f$ (Figure 3c) exhibited two main peaks arising from $4 f_{5 / 2}$ at $164.5 \mathrm{eV}$ and $4 f_{7 / 2}$ at $159.2 \mathrm{eV}$, indicating the characteristic +3 oxidation state of $\mathrm{Bi}$ [28]. There are two additional peaks that can be distinguished in the BWO-0.18 spectrum with lower binding energies at 162.5 and $157.2 \mathrm{eV}$, which can be ascribed to the relatively low valence states of oxygen vacancy-connected $\mathrm{Bi}$ atoms. The OV generation on iodine-doped $\mathrm{Bi}_{2} \mathrm{WO}_{6}$ was also confirmed via EPR measurement (Figure 3d). As expected, characteristic OV signals at $g=2.0001$ were observed for all the solvothermal synthesized iodine-doped $\mathrm{Bi}_{2} \mathrm{WO}_{6}$ catalysts, which showed an enhanced OV signal with the increase in the iodine doping concentration, thereby signifying the successful introduction of $\mathrm{OVs}$ on the $\mathrm{Bi}_{2} \mathrm{WO}_{6}$ surface. From the $\mathrm{N}_{2}$ adsorption-desorption isotherm measurement, the surface areas of BWO and BWO-0.18 were measured as 32.1 and $40.4 \mathrm{~m}^{2} / \mathrm{g}$, respectively, by the Brunauer-Emmett-Teller specific surface area analysis (Figure 3e). Although the materials did not show much difference in physical adsorption, the
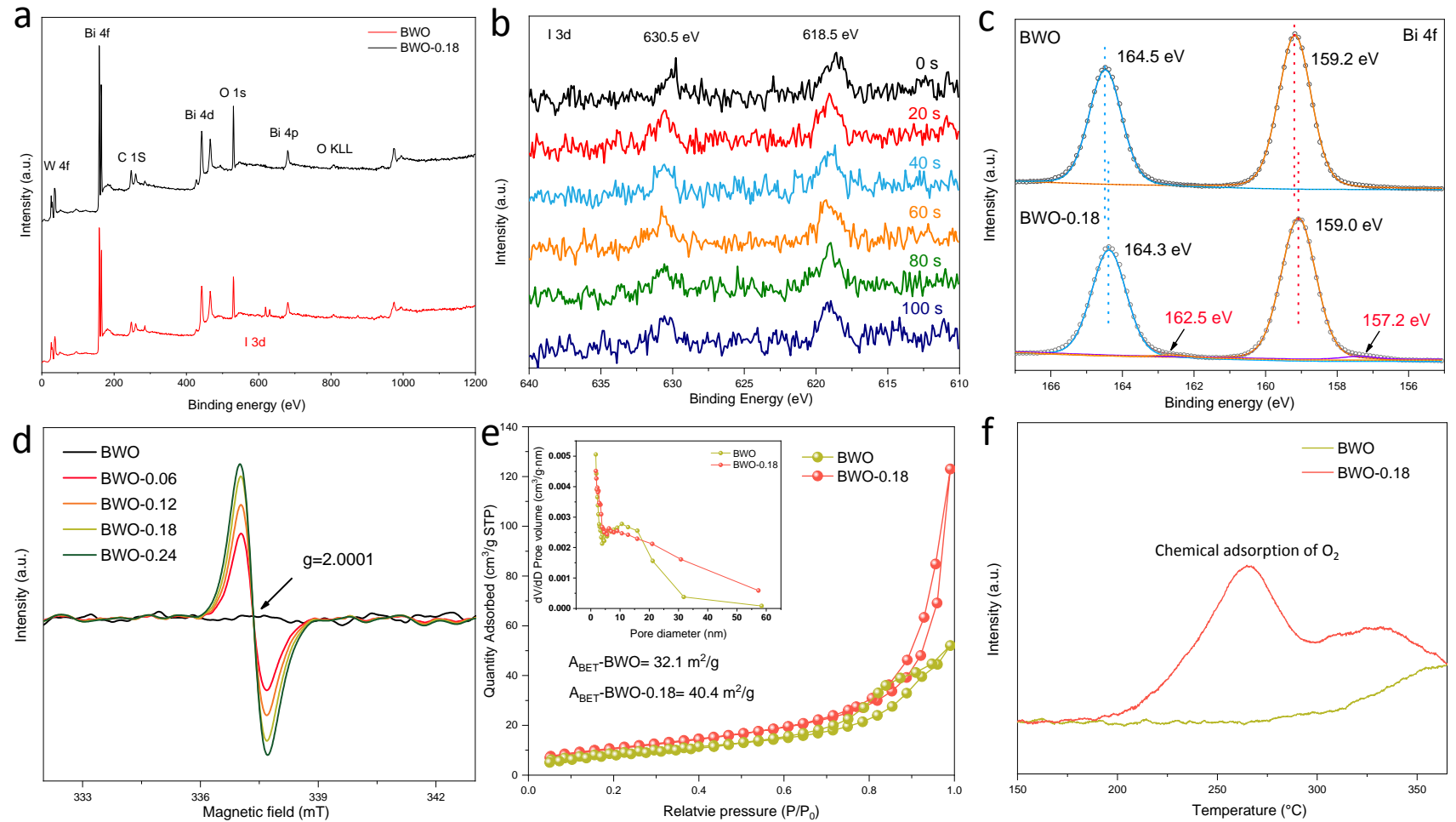

Fig. 3. Survey XPS spectra of BWO and BWO-0.18 (a), time-dependent high-resolution I 3d XPS spectra of BWO-0.18 (b) and Bi $4 f$ XPS spectra of BWO and BWO-0.18 (c); EPR spectra over pure $\mathrm{Bi}_{2} \mathrm{WO}_{6}$ and iodine-doped $\mathrm{Bi}_{2} \mathrm{WO}_{6}$ (d); physical adsorption (e) and chemical adsorption ( $\mathrm{f}$ ) of $\mathrm{BWO}$ and BWO-0.18. 
chemisorption of BW0-0.18 presented a significant enhancement in $\mathrm{O}_{2}$ chemisorption in comparison to that presented by BWO (Figure 3f), which is widely believed to has a catalytic effect on the molecular oxygen activation [48]. According to the above results, we can infer that OVs were successfully introduced into $\mathrm{Bi}_{2} \mathrm{WO}_{6}$ via this facile solvothermal method. In addition, the amount of $\mathrm{OVs}_{\mathrm{V}}$ in $\mathrm{Bi}_{2} \mathrm{WO}_{6}$ increased significantly with the introducing of iodine dopants, which could provide a more convenient environment for molecular oxygen activation.

Generally, the absorption of light is the first step in photocatalytic reactions. The iodine-doped $\mathrm{Bi}_{2} \mathrm{WO}_{6}$ catalyst exhibited a trailing absorption in comparison to that of BWO around 450 $\mathrm{nm}$ to $700 \mathrm{~nm}$, as shown in the UV-Vis absorption spectra (Figure $4 \mathrm{a}$ ), which could be attributed to the sub-band excitation from defect states to the conduction band (CB) induced by the introduction of OVs and iodine dopant. The bandgap energies of BWO and BWO-0.18 were calculated to be 2.87 and $2.74 \mathrm{eV}$, respectively (inset of Figure 4a), implying an enhancement in the adsorption of BWO-0.18 in the visible light region. The degradation process of NaPCP requires the involvement of a large amount of ROS; thus, it was selected as the degradation target to evaluate the photocatalytic molecular oxygen activation ability of the as-prepared materials. As shown in Figure $4 \mathrm{~b}$, we evaluated and compared the photocatalytic activities of the as-prepared $\mathrm{Bi}_{2} \mathrm{WO}_{6}$ materials. Notably, all of the iodine-doped $\mathrm{Bi}_{2} \mathrm{WO}_{6}$ catalysts exhibited excellent photocatalytic performance for NaPCP degradation in comparison to that of the pure $\mathrm{Bi}_{2} \mathrm{WO}_{6}$. Among these iodine-doped $\mathrm{Bi}_{2} \mathrm{WO}_{6}$ samples, BWO-0.18 possessed the highest photocatalytic activity, as it could almost completely remove NaPCP within $60 \mathrm{~min}$. It should be pointed out that a high number of OVs can be introduced into $\mathrm{Bi}_{2} \mathrm{WO}_{6}$ with the continual addition of the iodine dopant, which may serve as recombination centers and hinder the separation of photogenerated carriers. Therefore, the photocatalytic performance of iodine-doped $\mathrm{Bi}_{2} \mathrm{WO}_{6}$ first gradually increased with the iodine dopant addition and then decreased, thereby implying that BWO-0.18 possesses the optimal doping ratio. The photocatalytic kinetic simulation indicates that the rate constant of the NaPCP degradation over BWO-0.18 was 268 times higher than over BWO, indicating that the visible light photocatalytic activity of BWO could be notably enhanced by iodine doping induced OVs (Figure 4c). In addition, the stability of BWO-0.18 was also evaluated by the photocatalytic degradation of NaPCP under visible light. Within five consecutive runs, the BWO- 0.18 catalyst still exhibited a relatively high removal rate, indicating the good stability of BWO-0.18 (Figure $4 \mathrm{~d})$. The TOC removal rate is an important indicator to investigate the complete oxidation of NaPCP. As shown in Figure 4e, the TOC content removal rates in the solution over BWO, BWO-0.18, and BWO-0.24 were evaluated. Consistent with the degradation efficiency, BWO-0.18 exhibited a TOC remove rate almost 12 times that of BWO, and the removal rate exceeded $90 \%$ in $2 \mathrm{~h}$, thereby demonstrating the deep oxidation of $\mathrm{NaPCP}$ with our iodine-doped $\mathrm{Bi}_{2} \mathrm{WO}_{6}$ employed as photocatalysts. Subsequently, we also evaluated the role of each radical in the process of degradation by adding scavengers. As shown in Figure 4f, the scavenger of triethanolamine (TEOA) for photogenerated holes completely inhibited the photodegradation of
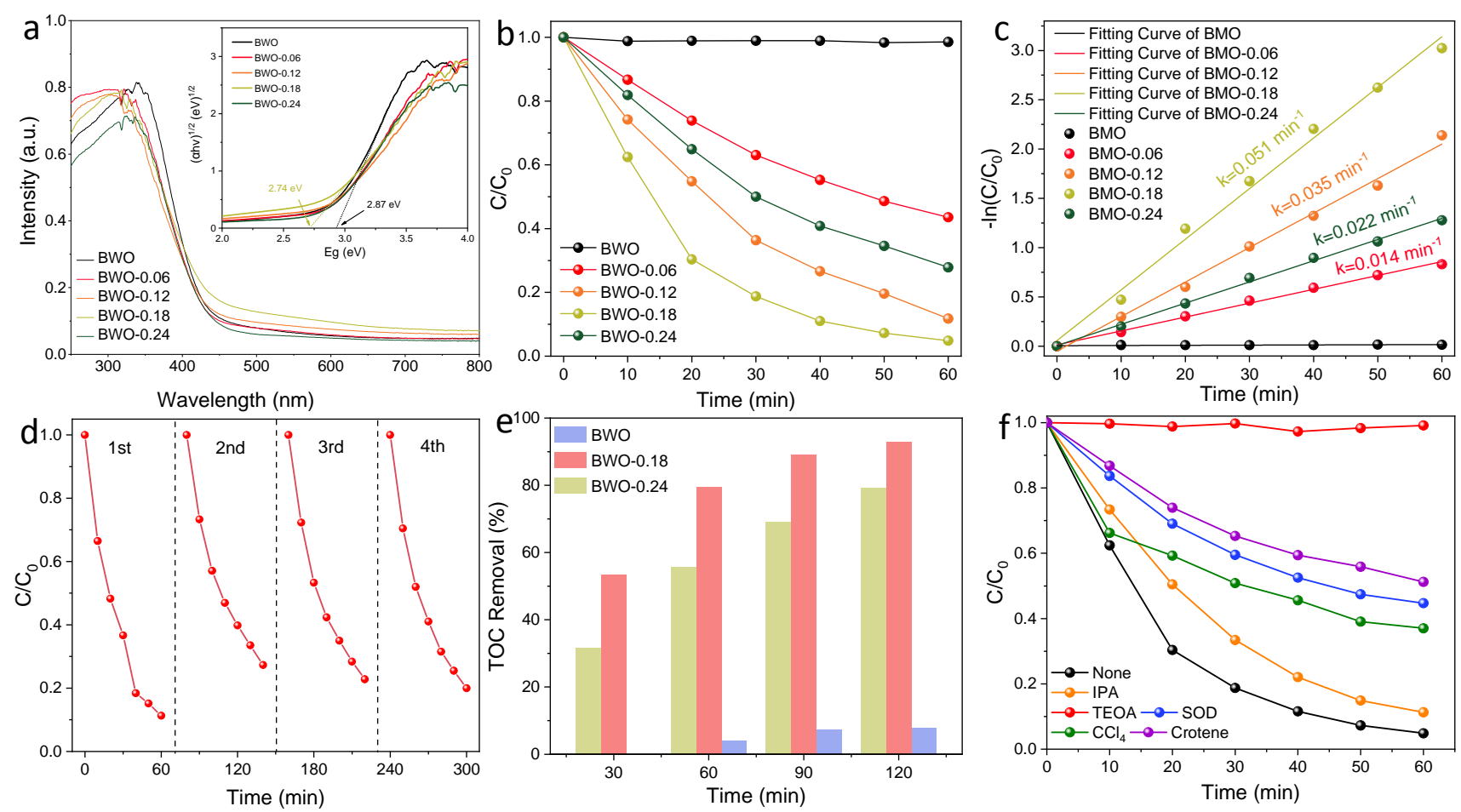

Fig. 4. DRS spectra (a), NaPCP photodegradation efficiency (b), corresponding photocatalytic kinetic simulation (c) of the as-prepared materials; photodegradation stability (d), TOC removal efficiency (e) and trapping measurement with different scavengers (f) using BWO-0.18 as the photocatalyst. 
NaPCP, while the scavenger of isopropanol (IPA) for hydroxyl radicals slightly affected its photodegradation. The other scavengers for electrons, ${ }^{\cdot} \mathrm{O}_{2}{ }^{-}$and ${ }^{1} \mathrm{O}_{2}$, displayed relative high inhibition of the photodegradation, thereby indicating that the holes, ${ }^{\cdot} \mathrm{O}_{2}{ }^{-}$and ${ }^{1} \mathrm{O}_{2}$, were the main oxidative species in the photocatalytic degradation process.

To obtain more solid evidence for the advantages in enhancing the molecular oxygen activation over BWO-0.18, the EPR spectra were further employed as the detector for generated ROS in the presence of a spin trapping agent. As shown in Figure $5 \mathrm{a}$, the enhanced characteristic peaks of DMPO- $\mathrm{OH}$ can be observed in the solution with BWO as the catalyst after irradiation, while under the same condition of irradiation, BWO-0.18 did not show noticeably enhanced signals of DMPO- $\cdot \mathrm{OH}$. For DMPO- $\bullet_{2} \mathrm{O}^{-}$(Figure $5 \mathrm{~b}$ ), both of the catalysts evidently possess relatively strong DMPO- $\mathrm{O}_{2}{ }^{-}$signals under visible light irradiation, although the enhancement over BWO-0.18 was more pronounced. As illustrated in Figure 5c, visible light irradiated BWO-0.18 showed an enhanced triplet signal, which can be indexed to ${ }^{1} \mathrm{O}_{2}$. Compared to the sample without irradiation, the enhancement of the ESR intensity in BWO-0.18 was much higher than that in BMO, which is attributed to the stronger ability of ${ }^{1} \mathrm{O}_{2}$ generation. Generally, ${ }^{1} \mathrm{O}_{2}$ could be converted via two different pathways: from the charge transfer process, in which ${ }^{1} \mathrm{O}_{2}$ generates from the ${ }^{\circ} \mathrm{O}_{2}{ }^{-}$species oxidized by holes, and from the energy transfer, in which $\mathrm{O}_{2}$ absorbs the energy generated by electron-hole recombination and transforms into ${ }^{1} \mathrm{O}_{2}$ directly. Therefore, the contributions of the charge and energy transfer processes for ${ }^{1} \mathrm{O}_{2}$ generation in BW0-0.18 were subsequently distinguished by selecting superoxide dismutase (SOD) and nitrogen (Figure 5d). With the addition of SOD or in nitrogen atmosphere, BWO-0.18 did not change the ${ }^{1} \mathrm{O}_{2}$ concentration in response to irradiation, and both of them held a relatively low concentration of ${ }^{1} \mathrm{O}_{2}$, indicating that the ${ }^{1} \mathrm{O}_{2}$ species is mainly produced through the electron transfer pathways for BWO-0.18. Furthermore, using the VB-XPS and Mott-Schottky plot (Figure 5e), the valence band (VB) positions of BWO and BWO-0.18 could be directly obtained by the equation based on our previously reported work, and the CB positions of BWO and BWO-0.18 could also be determined combined with the obtained bandgap value [20]. Therefore, the VB positions of BWO and BWO-0.18 were calculated to be 2.03 and $1.66 \mathrm{eV}$, respectively. Accordingly, the $\mathrm{CB}$ positions of BWO and BWO-0.18 were calculated to be -0.84 and $-1.07 \mathrm{eV}$, respectively. As shown in Figure 5f, the VB of BWO is positive enough for $\cdot \mathrm{OH}$ generation, while the $\mathrm{VB}$ of BWO-0.18 does not exhibit enough potential to produce $\cdot \mathrm{OH}$. In addition, the CB values of BWO and BWO-0.18 are both negative enough to transfer the electron on them to the absorbed oxygen, thereby achieving the molecular oxygen activation. Moreover, BWO-0.18 possessed a highly negative CB position and relatively large number of OVs; therefore, the molecular oxygen activation of BWO-0.18 is much stronger than that of BWO. These are highly consistent with the detection of radicals
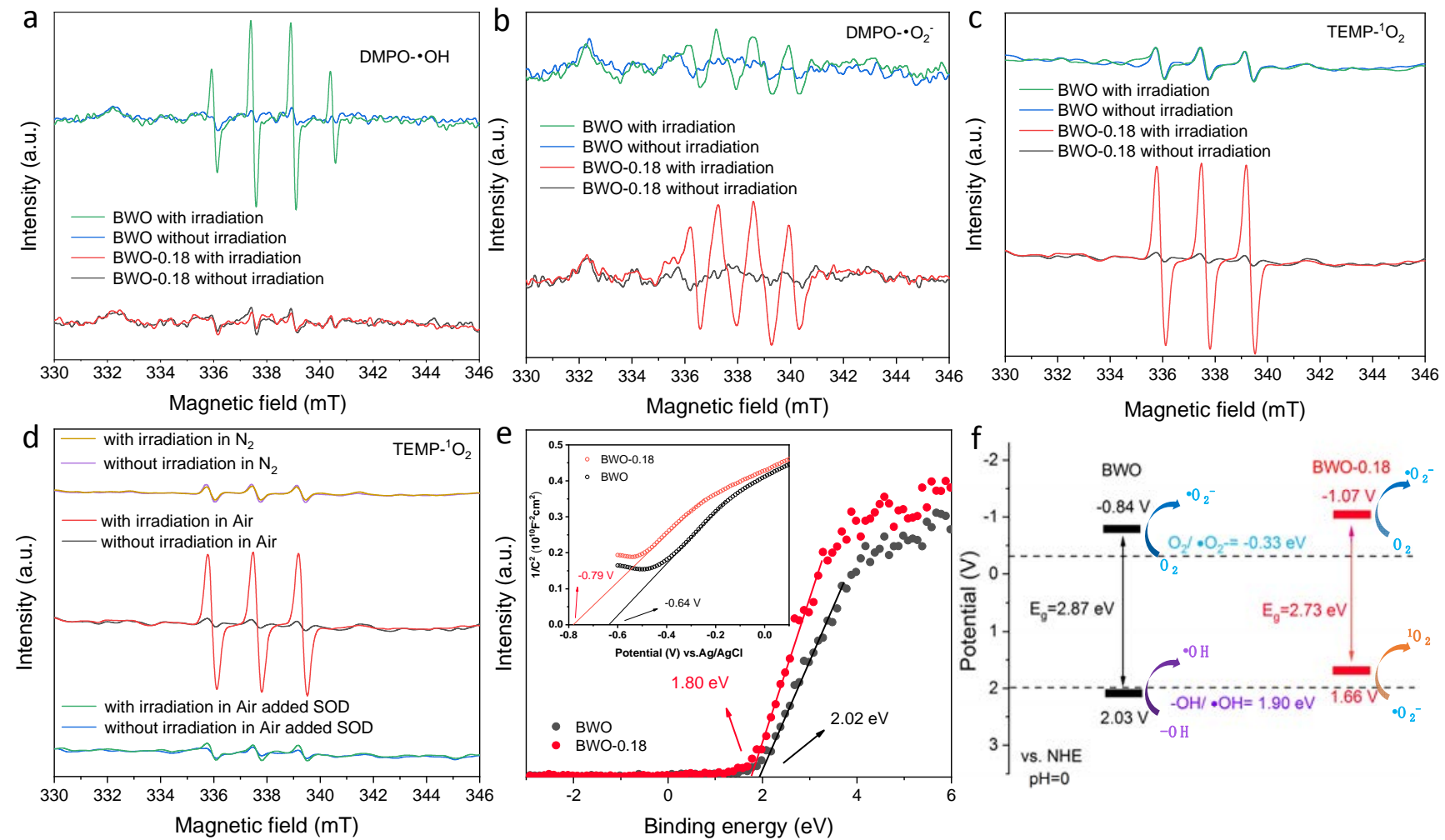

Fig. 5. ESR spectra of DMPO- $\mathrm{O}_{2}-(\mathrm{a})$, DMPO- $\cdot \mathrm{OH}(\mathrm{b})$, and $\mathrm{TEMP}-1 \mathrm{O}_{2}$ (c) over BWO and BWO-0.18 with or without irradiation. Comparison of the ESR spectra of TEMP- ${ }^{1} \mathrm{O}_{2}$ over BWO-0.18 under different conditions (d). The VB XPS spectrum (e), the Mott-Schottky plots (inset), and the corresponding band structures (f) of BWO and BWO-0.18. 


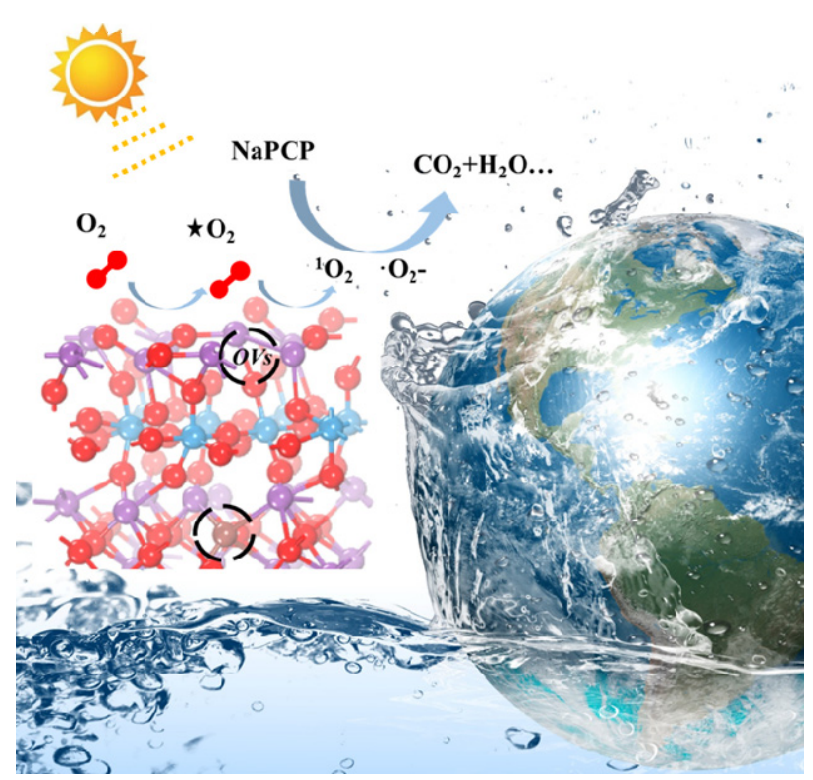

Scheme 1. Proposed mechanism for the photocatalytic degradation of $\mathrm{NaPCP}$ over iodine-doped $\mathrm{Bi}_{2} \mathrm{WO}_{6}$ under visible light irradiation.

by EPR [49].

Based on the above results and discussion, a reasonable mechanism of the action of the iodine doped $\mathrm{Bi}_{2} \mathrm{WO}_{6}$ is proposed in Scheme 1. First, the iodine dopants combined with the $\mathrm{Bi}$ atoms, thus decreasing the energy of the Bi-O bonds, which promoted the generation of OVs on the $\mathrm{Bi}_{2} \mathrm{WO}_{6}$ surface. The introduced OVs in iodine-doped $\mathrm{Bi}_{2} \mathrm{WO}_{6}$ could not only localize photogenerated electrons but also act as active sites for molecular oxygen activation. With the coordination of OVs and iodine doping, the optimized iodine-doped $\mathrm{Bi}_{2} \mathrm{WO}_{6}$ (BWO-0.18) exhibited enhanced molecular oxygen activation, producing a large number of ROS under light irradiation. With the enhanced molecular oxygen activation induced by OVs, the TOC removal rate of BWO-0.18 was 10.6 times higher than that of BWO under visible light irradiation.

\section{Conclusions}

A novel iodine-doped $\mathrm{Bi}_{2} \mathrm{WO}_{6}$ catalyst bearing OVs was synthesized via a simple solvothermal method. By adjusting the iodine dopant concentration, a high density of oxygen vacancies was successfully introduced by homogeneous iodine doping. The as-prepared $\mathrm{Bi}_{2} \mathrm{WO}_{6}$ catalyst was characterized by theoretical calculations and various characterization techniques, from which the OVs in $\mathrm{Bi}_{2} \mathrm{WO}_{6}$ were confirmed to be intensely correlated with the iodine dopant due to its weakening effect on lattice oxygen bonds. The high activity and TOC removal efficiency in the photocatalytic degradation of NaPCP were attributed to the molecular oxygen activation induced by the OVs. Moreover, the mechanism through which the degradation of NaPCP over iodine-doped $\mathrm{Bi}_{2} \mathrm{WO}_{6}$ is enhanced, was speculated by ROS detection. This work provides a new perspective for the enhanced photocatalytic degradation of organochlorine pesticides via $\mathrm{OV}$-induced molecular oxygen activation over iodine-doped $\mathrm{Bi}_{2} \mathrm{WO}_{6}$ catalysts.

\section{References}

[1] P. Abhilash, N. Singh, J. Hazard. Mater., 2009, 165, 1-2.

[2] J. Liu, J. Diamond, Nature, 2005, 435, 1179-1186.

[3] Y. Xing, Y. Lu, R. W. Dawson, Y. Shi, H. Zhang, T. Wang, W. Liu, H. Ren, Chemosphere, 2005, 60, 731-739.

[4] F. P. Carvalho, Environ. Sci. Polic., 2006, 9, 685-692.

[5] J. Fu, B. Mai, G. Sheng, G. Zhang, X. Wang, P. Peng, X. Xiao, R. Ran, F. Cheng, X. Peng, Z. Wang, U. Tang, Chemosphere, 2003, 52, 1411-1422.

[6] T. Bøhn, M. Cuhra, T. Traavik, M. Sanden, J. Fagan, R. Primicerio, Food Chem., 2014, 153, 207-215.

[7] P. H. Howard, J. Saxena, H. Sikka, Environ. Sci. Technol., 1978, 12, 398-407.

[8] R. Andreozzi, V. Caprio, A. Insola, R. Marotta, Catal. Today, 1999, 53, 51-59.

[9] S. Esplugas, D. M. Bila, L. G. T. Krause, M. Dezotti, J. Hazard. Mater., 2007, 149, 631-642.

\section{Graphical Abstract}

Chin. J. Catal., 2020, 41: 1544-1553 doi: S1872-2067(19)63506-0

\section{Iodine-doping-assisted tunable introduction of oxygen vacancies on bismuth tungstate photocatalysts for highly efficient molecular oxygen activation and pentachlorophenol mineralization}

Shengyao Wang, Zhongliang Xiong, Nan Yang, Xing Ding *, Hao Chen * Huazhong Agricultural University, China

By adjusting the iodine dopants in $\mathrm{Bi}_{2} \mathrm{WO}_{6}$, a high density of oxygen vacancies was introduced through homogeneous iodine doping, which remarkably enhanced the molecular oxygen activation and pentachlorophenol mineralization under visible light irradiation.

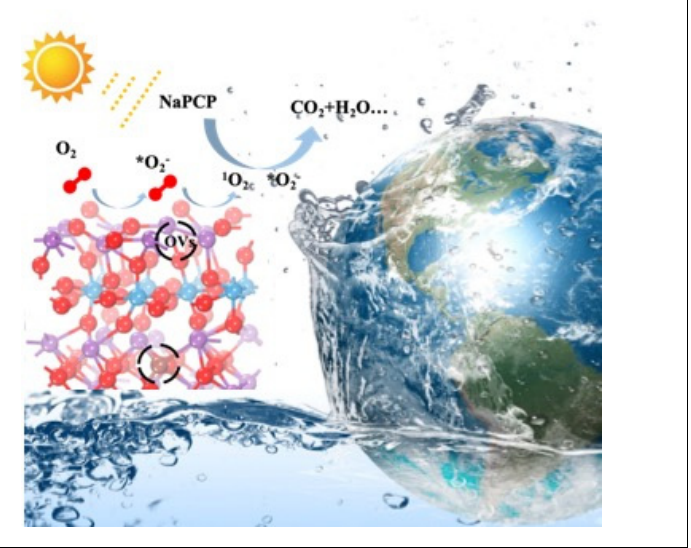


[10] T. An, H. Yang, W. Song, G. Li, H. Luo, W. J. Cooper, J. Phys. Chem. A, 2010, 114, 2569-2575.

[11] J. M. Herrmann, Catal. Today, 1999, 53, 115-129.

[12] A. Fujishima, K. Honda, Nature, 1972, 238, 37-38.

[13] J. Di, J. Xia, M. Ji, B. Wang, S. Yin, Q. Zhang, Z. Chen, H. Li, ACS Appl. Mater. Interfaces, 2015, 7, 20111-20123.

[14] M. Pelaez, N. T. Nolan, S. C. Pillai, M. K. Seery, P. Falaras, A. G. Kontos, P. S. Dunlop, J. W. Hamilton, J. A. Byrne, K. O'shea, Appl. Catal. B-Environ., 2012, 125, 331-349.

[15] J. Li, Y. Yu, L. Zhang, Nanoscale, 2014, 6, 8473-8488.

[16] Z. Wang, Y. Huang, M. Chen, X. Shi, Y. Zhang, J. Cao, W. Ho, S. C. Lee, ACS Appl. Mater. Interfaces, 2019, 11, 10651-10662.

[17] Y. Huang, P. Wang, Z. Wang, Y. Rao, J. J. Cao, S. Pu, W. Ho, S. C. Lee, Appl. Catal. B-Environ., 2019, 240, 122-131.

[18] M. Chen, Y. Huang, J. Yao, J. J. Cao, Y. Liu, Appl. Surf. Sci., 2018, 430, 137-144.

[19] S. Wang, X. Yang, X. Zhang, X. Ding, Z. Yang, K. Dai, H. Chen, Appl. Surf. Sci., 2017, 391, 194-201.

[20] S. Wang, X. Ding, X. Zhang, H. Pang, X. Hai, G. Zhan, W. Zhou, H. Song, L. Zhang, H. Chen, Adv. Funct. Mater., 2017, 27, 1703923.

[21] J. Zhang, S. Wang, F. Liu, X. Fu, G. Ma, M. Hou, Z. Tang, Acta Phys.-Chem. Sin., 2019, 35, 885-895.

[22] S. Gu, L. Wang, J. Zhang, Chin. J. Chem., 2017, 35, 153-158.

[23] X. Yang, Y. Wang, X. Xu, Y. Qu, X. Ding, H. Chen, Chin. J. Catal., 2017, 38, 260-269.

[24] J. Wang, Z. Wang, B. Huang, Y. Ma, Y. Liu, X. Qin, X. Zhang, Y. Dai, ACS Appl. Mater. Interfaces, 2012, 4, 4024-4030.

[25] M. Setvín, U. Aschauer, P. Scheiber, Y. F. Li, W. Hou, M. Schmid, A. Selloni, U. Diebold, Science, 2013, 341, 988-991.

[26] E. Carter, A. F. Carley, D. M. Murphy, J. Phys. Chem. C, 2007, 111, 10630-10638.

[27] X. Xu, X. Ding, X. Yang, P. Wang, S. Li, Z. Lu, H. Chen, J. Hazard. Mater., 2019, 364, 691-699.

[28] Z. Zhang, W. Wang, E. Gao, M. Shang, J. Xu, J. Hazard. Mater., 2011, 196, 255-262.

[29] Q. Wu, R. Van De Krol, J. Am. Chem. Soc., 2012, 134, 9369-9375.
[30] Y. Lv, Y. Liu, Y. Zhu, Y. Zhu, J. Mater. Chem. A, 2014, 2, 1174-1182.

[31] L. Ye, K. Deng, F. Xu, L. Tian, T. Peng, L. Zan, Phys. Chem. Chem. Phys., 2012, 14, 82-85.

[32] Y. He, X. Jin, W. Li, S. Yang, B. Lu, Chin. J. Inog. Chem., 2019, 35, 996-1004

[33] H. Huang, S. Tu, C. Zeng, T. Zhang, A. H. Reshak, Y. Zhang, Angew. Chem. Int. Ed., 2017, 56, 11860-11864.

[34] R. Long, K. Mao, X. Ye, W. Yan, Y. Huang, J. Wang, Y. Fu, X. Wang, X. Wu, Y. Xie, J. Am. Chem. Soc., 2013, 135, 3200-3207.

[35] N. Zhang, X. Li, H. Ye, S. Chen, H. Ju, D. Liu, Y. Lin, W. Ye, C. Wang, Q. Xu, J. Am. Chem. Soc., 2016, 138, 8928-8935.

[36] H. Fu, C. Pan, W. Yao, Y. Zhu, J. Phys. Chem. B, 2005, 109, 22432-22439.

[37] C. Zhang, Y. Zhu, Chem. Mater., 2005, 17, 3537-3545.

[38] H. Fu, L. Zhang, W. Yao, Y. Zhu, Appl. Catal. B-Environ., 2006, 66, 100-110.

[39] R. Shi, G. Huang, J. Lin, Y. Zhu, J. Phys. Chem. C, 2009, 113, 19633-19638.

[40] C. Jovalekic, L. Atanasoska, V. Petrovic, M. Ristic, J. Mater. Sci., 1991, 26, 3553-3564.

[41] G. Kresse, J. Furthmüller, Phys. Rev. B, 1996, 54, 11169-11186.

[42] G. Kresse, D. Joubert, Phys. Rev. B, 1999, 59, 1758-1775.

[43] P.E. Blöchl, Phys. Rev. B, 1994, 50, 17953-17979.

[44] J. P. Perdew, K. Burke, M. Ernzerhof, Phys. Rev. Lett., 1996, 77, 3865.

[45] L. Wang, Z. Wang, L. Zhang, C. Hu, Chem. Eng. J., 2018, 352, 664-672.

[46] G. Zhang, Z. Hu, M. Sun, Y. Liu, L. Liu, H. Liu, C. P. Huang, J. Qu, J. Li, Adv. Funct. Mater., 2015, 25, 3726-3734.

[47] Y. Zhou, Y. Zhang, M. Lin, J. Long, Z. Zhang, H. Lin, J. C. S. Wu, X. Wang, Nat. Commun., 2015, 6, 8340.

[48] S. Wang, X. Hai, X. Ding, K. Chang, Y. Xiang, X. Meng, Z. Yang, H. Chen, J. Ye, Adv. Mater., 2017, 29, 1701774.

[49] X. Ding, K. Zhao, L. Zhang, Environ. Sci. Technol., 2014, 48, 5823-5831.

\title{
基于钼酸铋的磺掺杂辅助氧空位可控引入及其高效活化分子氧和矿化五氯酚作用
}

\author{
汪圣尧 ${ }^{\dagger}$, 熊中亮 ${ }^{\dagger}$, 杨 楠, 丁 星 ${ }^{\#}$, 陈 浩 ${ }^{*}$ \\ 华中农业大学理学院, 湖北武汉 430070
}

摘要: 氧空位引入是设计带隙和电子结构以显著提高半导体光催化效率的有效策略之一. 氧空位不仅可以有效地捕获载 流子而加速光生电子空穴对的分离, 还可以捕获电子作为惰性气体分子活化的活性位点. 在分子水平上阐明氧空位在光 催化中的固有功能也逐渐引起了研究者们的广泛兴趣. 近年来, 诸多文献报道原生氧空位可以很容易地通过局域电子对 氧气进行充电, 这表明光催化是分子氧在氧空位上的活化是克服三重态 $\mathrm{O}_{2}$ 自旋禁制反应生成活性氧物种的可靠选择. 由 此产生的活性氧物种, 如羟基自由基( $(\mathrm{OH}) 、$ 超氧阴离子自由基 $\left({ }^{\circ} \mathrm{O}_{2}{ }^{-}\right)$和单线态氧 $\left({ }^{1} \mathrm{O}_{2}\right)$, 通常比 $\mathrm{O}_{2}$ 更具有氧化性. 尽管在构建 氧空位方面已有系列开创性的工作报道, 但在光催化材料上氧空位浓度的调控策略仍处于起步阶段, 依然具有很大的探索 空间. 因此, 建立一种可控引入氧空位的方法, 并揭示氧空位在增强分子氧活化中的潜在作用具有重要科学意义. 我们利 用还原性的乙二醇为溶剂, 通过简便的溶剂热法合成了氧空位浓度可控的碘掺杂铇酸铋. 在理论计算预测的基础上, 采用 X射线粉末衍射(XRD)、透射电子显微技术(TEM)、X射线光电子能谱(XPS)、电感耦合等离子体光谱(ICP)、拉曼光谱(Raman) 和电子顺磁共振波谱(EPR)等多种表征手段研究了碘掺杂对铇酸铋氧空位构筑及理化性质的影响.

理论计算结果表明, 未改性铇酸铋需要 $2.94 \mathrm{eV}$ 的能量驱使晶格氧原子逸出形成氧空位, 而表面碘掺杂可以将该能垒降 至 $1.20 \mathrm{eV}$, 证明了硾掺杂可以降低铇酸铋氧空位的形成能, 从而促进铇酸铋上氧空位的生成. 受此启发, 我们利用溶剂热 法合成了系列碘掺杂铇酸铋, XRD和形貌分析表明碘的引入并未改变铇酸铋的结构. 而XPS和ICP分析证实了碘的成功引 入. EPR结果显示随着磺含量的增加, 铇酸铋的氧空位浓度也逐渐提高, 证明了碘的引入促进了氧空位的产生. 通过对五 
氯酚钠的光催化降解实验, 我们进一步研究了碘诱导产生的氧空位对材料光催化活性的影响. 结果表明, 所有碘掺杂的铇 酸铋在可见光辐照下都表现出更高的五氯酚钠降解活性, 优化后的碘掺杂钨酸铋在 $2 \mathrm{~h}$ 内对五氯酚钠的总有机碳去除率即 可超过 $90 \%$. 为进一步分析碘掺杂铇酸铋光催化活性提高的原因, 我们分别对样品进行了比表面测试、氧气吸附量测试及 能带位置和活性物种分析. 结果表明, 碘元素的掺杂虽然没有明显拓展铇酸铋的吸收带边, 但是可以提高钨酸铋材料在可 见光区的光吸收能力, 促进材料对光的利用率. 更重要的是, 氧空位的引入显著增强了铇酸铋对氧气的化学吸附, 因而增 强了其在可见光下通过活化分子氧作用, 进而产生更多的超氧自由基和单线态氧促进光催化五氯酚降解. 该研究为实现 可控构筑含氧空位光催化材料用于环境污染物降解提供了新的思路.

关键词: 碘掺杂; 氧空位; 钨酸铋; 光催化; 分子氧活化; 五氯酚钠

收稿日期: 2020-02-27. 接受日期: 2020-03-30. 出版日期: 2020-10-05.

*通讯联系人. 电话/传真: (027)87288246; 电子信箱: hchenhao@mail.hzau.edu.cn

\#通讯联系人. 电话/传真: (027)87288246; 电子信箱: dingx@mail.hzau.edu.cn

基金来源：国家自然科学基金(51872107，21607047，51572101，51902121); 湖北省自然科学基金(2016CFB193, 2019CFB322); 中 央高校基本科研业务费专项基金(2662015QD047, 2662016PY088, 2662015PY047).

本文的电子版全文由Elsevier出版社在ScienceDirect上出版(http://www.sciencedirect.com/science/journal/18722067). 